TITLE:

\title{
Diversity and functioning of fungi associated with leaf litter decomposition in Asian forests of different climatic regions
}

\author{
$\operatorname{AUTHOR}(\mathrm{S})$ : \\ Osono, Takashi
}

\section{CITATION:}

Osono, Takashi. Diversity and functioning of fungi associated with leaf litter

decomposition in Asian forests of different climatic regions. Fungal Ecology 2011, 4(6): 375-385

\section{ISSUE DATE:}

2011-12

URL:

http://hdl.handle.net/2433/148002

\section{RIGHT:}

Copyright (C) 2011 Elsevier Ltd and The British Mycological Society. All rights reserved.; こ の論文は出版社版でありません。引用の際には出版社版をご確認ご利用ください。; This is not the published version. Please cite only the published version. 
Diversity and functioning of fungi associated with leaf litter decomposition in

Asian forests of different climatic regions

Takashi Osono*

Center for Ecological Research, Kyoto University

1-30-923 Hirano, Otsu, Shiga 520-2113, Japan

* Corresponding author. Tel.: +81 77549 8252; fax: +81 775498201.

E-mail address: tosono@ecology.kyoto-u.ac.jp

URL: http://www.ecology.kyoto-u.ac.jp/ tosono/

\begin{abstract}
I investigated the pattern of diversity and functioning of fungi associated with

leaf litter decomposition in Asian forests of different climatic regions by performing meta-analysis of published data for seven tree species in subalpine, temperate, subtropical, and tropical forests. Fungal assemblages were examined
\end{abstract}


by using common standard isolation-culture methods, and the abilities of individual fungal species to decompose leaf litter were examined with pure culture decomposition tests. The climatic patterns of diversity, assemblage structure, and genus composition depended on the method of isolation: the washing method revealed no consistent pattern, whereas the surface disinfection method showed lower diversity and greater relative abundance of dominant fungal species within the assemblages in cooler climates. The decomposing ability of fungal species that exhibited the greatest ability among the fungal assemblages was greater in warmer than in cooler climates and in broad-leaved than in coniferous tree species. In particular, the greatest abilities to cause mass loss were found among fungi with ligninolytic activity in broad-leaved tree species in warmer climates.

Keywords: climate, decomposition, forest, fungi, leaf litter

\section{Introduction}


Fungi are a major component of the biodiversity in forest ecosystems and play crucial roles in decomposition processes, facilitating soil nutrient recycling and the accumulation of soil organic matter (Cooke and Rayner 1984). Fungi can serve as indicators of environmental changes resulting from natural or anthropogenic causes, such as global warming and elevated carbon dioxide levels (Frankland et al. 1995; Treseder 2005). Understanding the climatic patterns of the distribution of fungi associated with leaf litter decomposition is crucial, as it will provide useful insights into the future changes of biodiversity and functioning of forest ecosystems in response to global warming. However, only a few studies have examined the geographic distribution of saprobic fungi among different climatic regions. Tokumasu (2001) demonstrated that the occurrence of Sporidesmium goidanichii on pine needle litter was related to temperature from boreal to subtropical regions in Japan. Yet, much still remains unknown about the patterns of species richness and composition of fungi along gradients of climatic regions. It is hypothesized that saprobic fungi, like endophytic fungi (Arnold and Lutzoni 2007), can be more diverse in terms of species richness, and consequently of functioning, in warmer and wetter climates along climatic gradients, as has 
been demonstrated for the general latitudinal gradient of diversity (Hillebrand 2004), but there have been no data to verify this hypothesis for saprobic fungi (Hyde et al. 2006; Amend et al. 2010). To my knowledge, furthermore, information is lacking regarding the climatic patterns of functional aspects of fungal assemblages associated with leaf litter decomposition.

I tested the hypothesis by synthesizing previously published data on the assemblages and decomposing abilities of fungi associated with the decomposition of leaf litter from different climatic regions. I have contributed to studies of fungal diversity and functioning on seven tree species (four broad-leaved and three coniferous ones) in subalpine, temperate, subtropical, and tropical forests in Japan and Thailand and published papers from 2002 to 2009 (Tables 1, 2, 3). I conducted these studies with common methodologies in the same laboratory, making it possible to compare the results of the studies directly and to investigate possible climatic patterns of fungal diversity and functioning. Based on these results, I will discuss the fungal assemblages as a possible explanatory variable for predicting the decomposition in the field. Because the number of tree species (i.e., seven) is too low to provide statistically meaningful conclusions about the 
hypotheses, my final purpose here will be to suggest further hypotheses for the study of fungal diversity and functioning in different climatic regions.

\section{Materials and methods}

Tree species and study sites

I synthesized the data of fungal assemblages from seven tree species

(four broad-leaved and three coniferous ones) in five climatic regions for the

present study (Table 1). Subalpine, cool and warm temperate, and subtropical forests were located in Japan and a tropical forest in Thailand. Mean annual temperature ranged from 2 to $25^{\circ} \mathrm{C}$ and mean annual precipitation from 940 to $2500 \mathrm{~mm}$. The seven tree species were major components of the respective forest stands. Leaf litter of two Abies species from the subalpine forest (A. mariesii and A. veitchii) was similar in their morphological characteristics and difficult to distinguish from each other; thus, they were simply identified to the genus level (Osono and Takeda 2006, 2007). In the present study, I refer to the seven tree taxa 
by genus names for the sake of simplicity.

Fungal assemblages

Fungal assemblages on leaf litter of the seven tree species were examined

with common methods of fungal isolation in the same laboratory, but the methods

of collection or preparation of leaf litter used for the fungal isolation were somewhat different among the studies. Leaf litter of Abies, Betula, and Fagus was collected directly from the surface of the forest floor three or six times during growing seasons; that of Larix from both litter and fermentation layers of the forest floor on a single sampling occasion; and that of Chamaecyparis used for the surface disinfection method and Castanopsis from the surface of the forest floor on a single sampling occasion. Leaf litter of Chamaecyparis used for the washing method was enclosed in litterbags and incubated on the forest floor and was retrieved one time, one year after the placement. Shorea litter enclosed in litterbags was retrieved three times during a 9-month period. Fungi of Castanopsis and Shorea were isolated from both bleached and adjacent 
nonbleached portions of each single leaf litter sample. Details of the sample preparation were described in the original papers (Table 2).

In summary, sterile $6-\mathrm{mm}$ or $5.5-\mathrm{mm}$-diameter cork borers were used to excise leaf disks from leaves of broad-leaved tree species, whereas for coniferous tree species single needles were used for fungal isolation. A total of 20 to 120 leaf disks or needles per tree species (Table 2) were treated with the washing (W) method of Harley and Waid (1955) and/or the surface disinfection (SD) method of Kinkel and Andrews (1988). These have been two of the most common methods used for the study of fungal diversity on leaf litter (Kendrick and Burges 1962; Przybyl et al. 2008). The treated samples were placed on lignocellulose agar (LCA) (Miura and Kudo 1970), and incubated at $20^{\circ} \mathrm{C}$ for 8 to 12 weeks to isolate fungi according to the method described in Osono and Takeda (1999b). LCA contains glucose $0.1 \%, \mathrm{KH}_{2} \mathrm{PO}_{4} 0.1 \%, \mathrm{MgSO}_{4} \cdot 7 \mathrm{H}_{2} \mathrm{O} 0.02 \%, \mathrm{KCl} 0.02 \%, \mathrm{NaNO}_{3} 0.2 \%$, yeast extract $0.02 \%$, and agar $1.3 \%(\mathrm{w} / \mathrm{v})$. LCA was used because its low glucose content suppresses the overgrowth of fast-growing species and because it induces sporulation, which is useful for fungal identification (Osono and Takeda 1999b). Note that the LCA used in Miura and Kudo (1970) and in the present study does 
not contain lignin or other recalcitrant compounds. Any hyphae or spores on the plates were subcultured on fresh LCA plates, incubated, and identified to species, genus, or family. Identification was based on micromorphological observations, with reference to Domsch et al. (1980) and Ellis (1971, 1976). Some fungi were further identified by DNA analysis by the method described by Hirose and Osono (2006), using BLAST searching with reference to the data of known species deposited in Genbank database. The data of sterile mycelia were omitted in the present analysis. The frequency of individual fungal species was calculated as a percentage of incidence based on the number of samples with the species relative to the number of samples tested (i.e., 20 to 120 , Table 2).

In the present study, the top 15 (or fewer) fungal species in terms of frequency of occurrence were selected for each tree species and each isolation method to calculate similarities of composition of the fungal assemblages at the genus level. The similarities of genus composition among the fungal assemblages from different climatic regions or from different isolation methods were examined using a similarity index that was expressed by the following formula: similarity index $(\%)=$ the number of matches of fungal species at genus level between the 
two assemblages / the number of all combinations of fungal species between the two assemblages $\times 100$.

Decomposing ability of fungi

Isolates of fungi from the seven tree species were used to assay the ability to decompose leaf litter in the pure culture decomposition test with common methods in the same laboratory (Table 3). The number of fungal species examined for each tree species ranged from 8 to 37 (Table 3). In summary, leaves of the respective tree species without obvious fungal or faunal attack were collected in the study sites and used as substrata for the tests. The leaves were sterilized by autoclaving at $120^{\circ} \mathrm{C}$ for $15 \mathrm{~min}$ (Fagus) or by exposure to ethylene oxide gas at $60^{\circ} \mathrm{C}$ for 6 hours (the other six tree species). The sterilized leaves were placed on the surface of 9 -cm-diam. Petri dishes containing $20 \mathrm{~mL}$ of $2 \%$ agar. Using a sterile 6-mm-diam. cork borer, inocula for each assessment were excised from the margin of a colony actively growing on previously inoculated Petri dishes containing $2 \%$ malt-extract agar (2\% malt extract, $2 \%$ agar). Inocula were placed 
on the agar adjacent to leaves, one plug per plate. The plates were sealed with paraffin film and incubated for 8 (Fagus) or 12 weeks (the other six tree species) at $20^{\circ} \mathrm{C}$ in darkness. After incubation, the leaves were retrieved, oven-dried at $40^{\circ} \mathrm{C}$ to a constant mass, and weighed. Occurrence of bleaching on the surface of decomposed leaves was observed under a binocular microscope (40×). Three, four, or 10 plates were prepared for each isolate, and three, four, or 10 uninoculated plates served as a control. The undecomposed initial leaves were also sterilized, oven-dried at $40^{\circ} \mathrm{C}$ to a constant mass, and weighed to determine original mass. Loss of leaf mass was determined as a percentage of the original mass, taking the mass loss of control leaves into consideration. Prior to the experiments, the sterilized leaves were placed on $2 \%$ malt-extract agar, and after 8 or 12 weeks of incubation at $20^{\circ} \mathrm{C}$ in darkness, no microbial colonies had developed on the plates. Thus, the effectiveness of the sterilization methods used in individual studies was verified.

Caution must be taken when comparing the mass loss values of Fagus with the values of the other six tree species because of the difference in the method of sterilization and incubation period. Mass loss of leaves caused by a 
fungus can be 1.5-1.7 times greater when leaves are autoclaved than when they are gas-sterilized (T. Osono, unpublished data). The mass loss values examined with 8-week incubation for Fagus experiments can be regarded as being comparable to those with 12 -week incubation because preliminary experiments showed that mass loss of Fagus leaves caused by Xylaria sp. reached an asymptote after 8 weeks of incubation and were not significantly $(\mathrm{P}<0.05$, t-test $)$ different between 8 and 12 weeks of incubation.

Statistical analysis

The total number of fungal species in each tree species was used as an indicator of species richness (S). Simpson's diversity index (D) and equitability (E) were calculated using the following equations (Osono et al. 2002): $\mathrm{D}=1 / \Sigma \mathrm{P}^{2}$, $\mathrm{E}=\mathrm{D} / \mathrm{S}$, where $\mathrm{P} i$ is the relative frequency of the $i$ th species to the sum of the frequency in each fungal assemblage. D indicates the character of a fungal assemblage that takes into account both the relative frequency patterns and the species richness. E indicates the evenness with which fungi are distributed among 
the species.

To analyze the effect of tree species on fungal species richness, the number of fungal species was compared among tree species using an individual-based rarefaction curve (Gotelli and Colwell 2001). Approximate 95\% confidence intervals were calculated according to Coleman et al. (2004). This analysis was performed with EstimateS

(http://viceroy.eeb.uconn.edu/estimates).

\section{Results}

Fungal assemblages

Table 2 shows the species richness, Simpson's diversity index, and equitability of fungal assemblages for leaf litter of seven tree species. Species richness and Simpson's diversity index were greater in broad-leaved trees than in coniferous trees when compared within the same climatic regions. Species richness and Simpson's diversity index were generally greater when examined 
with the $\mathrm{W}$ method than with the SD method, but the difference tended to be smaller in warmer climates. Species richness and Simpson's diversity index examined with the SD method were greater in warmer climates. Species richness examined with the $\mathrm{W}$ method was not significantly correlated with mean annual temperature, whereas a significant positive correlation was found with the SD method (Fig. 1). Similarly, Simpson's diversity index examined with the W method was not significantly correlated with mean annual temperature, whereas a marginally significant positive correlation was found with the SD method (Fig. 1). Equitability ranged from 0.29 to 0.51 when examined with the $\mathrm{W}$ method and from 0.30 to 0.51 with the SD method, and it was similar between the W and SD methods and showed no consistent trend with the climate.

Pattern of fungal diversity

Rarefaction curves of the fungal assemblages did not approach a plateau for the seven trees species examined with the W and SD methods (Fig. 2). The number of fungal species with respect to the number of leaf disks examined with 
the $\mathrm{W}$ method was generally greater in broad-leaved than in coniferous tree species when compared within the same climatic regions and was similar among tree species within each of the examined broad-leaved or coniferous tree species, except that it was greater in Fagus than in Castanopsis. The number of fungal species with respect to the number of leaf disks was generally lower when examined with the SD method than with the $\mathrm{W}$ method: when examined with the SD method it differed among tree species and was greater in warmer than in cooler climates in both broad-leaved and coniferous tree species. Rarefaction curves of Shorea were similar between the W and SD methods.

Structure of fungal assemblages

The rank-frequency curves of the fungal assemblages are consistent with the patterns of species richness and diversity (Fig. 3). The overall patterns of rank-frequency curves were different between the $\mathrm{W}$ and SD methods. Rank-frequency curves with the $\mathrm{W}$ method were characterized by low relative abundance of the dominant fungal species. With $\mathrm{W}$ the method, the relative 
abundances of dominant fungi were generally lower in broad-leaved than in coniferous tree species. In contrast, the relative abundances of dominant fungi were greater when examined with the SD method than with the $\mathrm{W}$ method, the most frequent fungal species accounting for up to 37 to $52 \%$ of the fungal assemblages with the SD method. There were clear trends that the relative abundances of dominant fungi were lower in warmer climates when examined with the SD method in both broad-leaved and coniferous tree species. That is, the relative abundance of the most frequent species examined with the SD method was in the order: Betula $>$ Fagus $>$ Castanopsis $>$ Shorea for broad-leaved tree species and Larix > Chamaecyparis for coniferous tree species. The rank-frequency curves for Shorea leaf litter (tropical forest) were similar between the SD and W methods.

Major fungal genera

Table 4 shows the major fungal genera isolated from leaf litter of seven tree species with the $\mathrm{W}$ and $\mathrm{SD}$ methods. The $\mathrm{W}$ method revealed generally 
similar composition of fungal genera among broad-leaved and coniferous tree species from different climatic regions. The dominant constituents of fungi examined with the $\mathrm{W}$ method included species in the genera Trichoderma, Penicillium, and Zygomycetes (Mortierella, Mucor, and Umbelopsis). Cladosporium and Pestalotiopsis also occurred on several tree species using the W method. In contrast, the SD method showed the occurrence of Xylariaceae fungi and their anamorphs (Xylaria, Geniculosporium, and Nodulisporium) and the occasional detection of Basidiomycetes as well as Trichoderma, Penicillium, and Zygomycetes. Beltrania, Beltraniella, Cylindrocladium, and Gliocephalotrichum were isolated from Castanopsis and Shorea leaf litter with both the W and SD methods.

Similarity of composition of major fungal genera

The similarity indices of major fungal genera between tree species and between the SD and W methods are shown in Fig. 4. The similarity index between fungal assemblages was generally greater with the $\mathrm{W}$ than the SD method for 
broad-leaved and coniferous tree species (Fig. 4a). The similarity index for broad-leaved tree species was greater for adjacent climatic regions than for distal regions for both the $\mathrm{W}$ and $\mathrm{SD}$ methods, whereas this was not the case for coniferous tree species (Fig. 4a). The similarity index between the W and SD methods was greater in warmer climates when examined for a single broad-leaved and coniferous tree species (Fig. 4b).

Decomposing ability of fungi

Figure 5 shows the abilities of fungal species isolated from each of the seven tree species to decompose leaf litter under pure culture conditions. In each tree species, there was a wide variation in mass loss values among the fungal species tested. A few fungal species caused bleaching of leaf litter in three broad-leaved tree species, i.e. Fagus, Castanopsis, and Shorea, whereas no fungi tested did so in Betula, Abies, Larix, or Chamaecyparis. Fungi with bleaching activity were isolated with the SD method in Fagus and Castanopsis, while in Shorea both the SD and W methods detected fungi that had potential activities to 
bleach the litter. Fungi with bleaching activity in Fagus belonged to Xylariaceae in Ascomycetes, whereas those in Castanopsis and Shorea belonged to Basidiomycetes (Lachnocladiaceae) and Ascomycetes (Xylariaceae). The bleaching activity of some fungi was associated with larger values of mass loss than that of others within fungal assemblages of individual tree species. Overall, mass loss values were greater in warmer than in cooler climates and was greater in leaf litter of broad-leaved than coniferous tree species when compared within the same climatic regions (i.e. Betula vs Abies, Fagus vs Larix).

Decomposition of leaves by major fungi

Mass loss values were plotted for the five most frequent fungi isolated with the SD or $\mathrm{W}$ method for individual tree species (Fig. 6). In general, the mass loss values for the five most frequent fungi were larger on broad-leaved than on coniferous tree species. One or two of the most frequent fungi detected with the SD method showed bleaching activities associated with greater mass loss values on Fagus and Castanopsis. Because of the presence of bleaching fungi, the mass 
loss values were greater for the five most frequent fungi with the SD method than those with the W method on Fagus and Castanopsis, as well as Larix. In contrast, the mass loss values were greater for the five most frequent fungi with the W method than those with the SD method on Shorea. Comparison among broad-leaved tree species revealed that the mass loss values for the five most frequent species were greater on Fagus and Castanopsis than on Betula and Shorea, which was attributable to the presence/absence of fungi with bleaching activity. In coniferous tree species, the mass loss values for the five most frequent fungi were greater in warmer climates.

\section{Discussion}

The patterns of diversity, assemblage structure, and genus composition of fungi from different climatic regions depended on the method of isolation. The results obtained using the $\mathrm{W}$ method suggested that there were minor differences in the diversity and assemblage structure of fungi among forests of different climatic regions (Figs. 1, 2, 3), but that the genus composition differed to some 
extent between warmer and cooler climates (Table 4, Fig. 4). Beltrania, Beltraniella, Cylindrocladium, and Gliocephalotrichum, which were frequently isolated from Castanopsis and Shorea leaf litter with the W method, are common inhabitants of tropical forest soils (Bills and Polishook 1994; Parungao et al. 2002; Promputtha et al. 2002; Tokumasu and Aoki 2002; Tang et al. 2005; Paulus et al. 2006; Duong et al. 2008) but are generally rare in temperate or subalpine soils. This difference in genus composition, however, was not strikingly reflected by the pattern of diversity and assemblage structure of fungi in different climatic regions. This is partly because most of the fungi isolated with the $\mathrm{W}$ method can be regarded as opportunistic surface colonizers that grow rapidly in culture, such as Trichoderma, Penicillium, and some zygomycetous genera (Tokumasu 1998a, 1998b, Osono and Takeda 1999a). The composition of these fungi at the genus level was relatively similar among forests of different climatic regions (Hudson 1968, Bettucci and Roquebert 1995), leading to the generally similar pattern of diversity (Fig. 2) and assemblage structure (Fig. 3). In contrast, the W method did detect differences between broad-leaved and coniferous tree species in terms of diversity (Figs. 1 and 2) and assemblage structure (Fig. 3). Hudson (1968) noted 
that leaf litters of coniferous trees in general are more selective substrates for fungal colonization than broad-leaved ones and are colonized by some fungi specific to them. This can explain the lower diversity and the greater relative abundance of dominant fungi in coniferous tree species.

In contrast to the results obtained with the $\mathrm{W}$ method, a climatic pattern was found for the diversity and assemblage structure of fungi when examined with SD method. The diversity was lower and the relative abundance of dominant fungi was greater in cooler climates when examined with the SD method (Figs. 1, 2, 3). The frequently isolated fungi included the Xylariaceae in Fagus, Larix, and Chamaecyparis in temperate forests (Table 4). The frequent occurrence of Xylariaceae on surface-disinfected leaf litter has been reported repeatedly in Japan (Koide et al. 2005; Osono and Hirose 2009a). In Castanopsis and Shorea, basidiomycetes, 'tropical and subtropical fungal genera' (mentioned above), and/or other 'surface' fungi (mentioned above) occurred frequently in addition to the Xylariaceae (Table 4). The more competitive colonization of interior tissues by diverse fungi in warmer climates led to higher diversity and relatively lower dominance of particularly frequent species. Therefore, the SD method suggested a 
general latitudinal gradient of diversity for saprobic fungi associated with leaf litter decomposition.

The results of the present study suggested a climatic difference in the functioning of fungi: active decomposers causing greater mass loss of leaves were found in warmer climates (Fig. 5). This trend was found under conditions of constant incubation temperature (i.e., $20^{\circ} \mathrm{C}$ ) during the decomposition tests, but it should be noted that leaves of different tree species that had different quality were used in the tests, making it difficult to directly compare the patterns of the potential capabilities of fungal assemblages to decompose leaves of different tree species. Obviously, it is necessary to compare the decomposing abilities of fungi from different host trees using common, standard leaf materials. Despite this methodological difficulty, it is noteworthy that the greatest abilities to cause mass loss were found among fungi with bleaching activity in Fagus, Castanopsis, and Shorea. Bleaching of leaf litter is attributable to the selective decomposition of lignin by ligninolytic fungi (Osono 2007; Osono et al. in press). The greater activity of fungi to decompose leaf litter and lignin in warmer climates in the present study was consistent with the findings of previous studies on leaf litter 
decomposition (Takeda 1998) and on the occurrence of bleached areas on leaf litter

(Osono 2006). Fungi in Ascomycota and Basidiomycota with bleaching activities

cause lignin decomposition in leaf litter in both temperate and tropical forest soils,

which is similar to white-rot of wood (Osono 2006, 2007). The reported finding that fungi appeared to be less efficient in decomposing the litter of coniferous than broad-leaved tree species is partly attributable to the presence of guaiacyl lignin in gymnosperms, which is more recalcitrant than the guaiacyl-syringyl lignin present in angiosperms, and/or to the higher abundance of secondary compounds such as phenolics and terpenoids that inhibit fungal growth in coniferous compared to broad-leaved tree species (Eriksson et al. 1990).

The decomposing abilities for the most frequent fungi shown in Fig. 6 generally followed the same trend as that seen in Fig. 5, i.e., the mass loss values were greater in warmer than in cooler climates. The greatest values of mass loss were recorded for the dominant fungi in Ascomycota for Fagus and in Basidiomycota for Castanopsis isolated with the SD method (Fig. 6), suggesting that these fungi play central roles in decomposition in terms of their frequency of occurrence and potential abilities to decompose lignin in leaf litter. In contrast, 
fungi without bleaching activity dominated in leaf litter of subalpine and coniferous tree species. These results suggest that not only the decomposition rates but also the patterns of decomposition of lignin relative to other organic chemical components differ between subalpine and coniferous leaf litter and leaf litter of the broad-leaved trees in warmer climates. In fact, Osono (2006) showed that the area of bleached portions on the surface of broad-leaved leaf litter was larger in tropical than in temperate forests, suggesting that colonization of leaf litter by ligninolytic fungi can be greater in tropical forests. The lack of dominant fungi with bleaching activity in Shorea may be explained by the competition with other fungi discussed above and by the selectivity of isolation methods that favor rapid-growing fungi rather than slow-growing ones such as ligninolytic basidiomycetes and ascomycetes. Further studies will be necessary to evaluate the relative importance of ligninolytic fungi in the fungal assemblages and in the decomposition processes in tropical forest soils.

The dataset of the present study enables us to investigate the fungal diversity and functioning as possible predictive factors for decomposition in the field. Species richness, diversity, and equitability of fungal assemblages and mean 
values of mass loss caused by the dominant fungi were related to available data of decomposition rates of leaf litter for the seven tree species (Table 5). The decomposition rates of the seven tree species were studied with the litterbag method in the same locations as those in the present study (except for Larix) and expressed as an exponential function (Olson's k, Olson 1963). The decomposition rates were correlated significantly and positively with mean annual temperature and mean mass loss caused by the dominant fungi isolated with the $\mathrm{W}$ method, and significantly and negatively with the content of acid-unhydrolyzable residues (Klason lignin) (Table 5). Climatic and litter-quality variables are known to be good predictors of decomposition under field conditions (Swift et al. 1979; Berg and McClaugherty 2003). The number of tree species examined in the present study was too small to draw definitive conclusions from the results, but indicated that the fungal assemblages can be an explanatory variable for predicting the decomposition. More studies of the diversity and functioning of fungi associated with leaf litter decomposition under various climatic conditions will be necessary to confirm the general validity of this finding. Studies designed using altitudinal gradients with standardized substrata and methodologies, such as those of Osono 
and Hirose (2009b) and Hirose et al. (in press), are promising regarding verifying climatic effects on fungal diversity and functioning. Future studies using molecular biological techniques to evaluate fungal diversity, with special reference to functional genes responsible for the transformation of major structural components of leaf litter, such as lignin and cellulose, will be especially promising in this respect.

\section{Acknowledgments}

The author is grateful to co-authors of the original papers used in the present analysis for their collaboration, Mr. S. Matsuoka for help with statistical analysis, and to Dr. E. Nakajima for critical reading of the manuscript. This study was supported by the Global COE Program A06 to Kyoto University.

\section{References}

Amend AS, Seifert KA, Samson R, Bruns TD, 2010. Indoor fungal composition is 
geographically patterned and more diverse in temperate zones than in the tropics. PNAS 107: 13748-13753.

Arnold AE, Lutzoni F, 2007. Diversity and host range of foliar fungal endophytes: are tropical leaves biodiversity hotspots? Ecology 88: 541-549.

Berg B, McClaugherty C, 2003. Plant litter, decomposition, humus formation, and carbon sequestration. Springer, Berlin.

Bettucci L, Roquebert MF, 1995. Fungi from a tropical rain forest litter and soil: a preliminary study. Nova Hedwigia 61: 111-118.

Bills GF, Polishook JD, 1994. Abundance and diversity of fungi in leaf litter of a lowland rain forest in Costa Rica. Mycologia 86: 187-198.

Coleman BD, Mao CX, Chang J, 2004. Interpolating, extrapolating and comparing incidence-based species accumulation curves. Ecology 85: 2717-2727.

Cooke RC, Rayner ADM, 1984. Ecology of saprotrophic fungi. Longman, London.

Domsch KH, Gams W, Anderson TH, 1980. Compendium of Soil Fungi, Vol. 1 and 2. Academic Press, London, UK.

Duong LM, McKenzie EHC, Lumyong S, Hyde KD, 2008. Fungal succession on senescent leaves of Castanopsis diversifolia in Doi Suthep-Pui National 
Park, Thailand. Fungal Diversity 30: 23-36.

Ellis MB, 1971. Dematiaceous hyphomycetes. CAB International, Oxon, UK.

Ellis MB, 1976. More dematiaceous hyphomycetes. CAB International, Oxon, UK.

Ericksson KE, Blanchette RA, Ander P, 1990. Microbial and enzymatic degradation of wood and wood components. Springer, Berlin.

Frankland JC, Magan N, Gadd GM, 1995. Fungi and environmental change. Cambridge University Press, Cambridge.

Gotelli NJ, Colwell RK, 2001. Quantifying biodiversity: procedures and pitfalls in the measurement and comparison of species richness. Ecology Letters 4: 379-391.

Harley LL, Waid JS, 1955. A method of studying active mycelia on living roots and other surfaces in the soil. Transactions of the British Mycological Society 38: $104-118$.

Hillebrand H, 2004. On the generality of the latitudinal diversity gradient. American Naturalist 163: 192-211.

Hirose D, Osono T, 2006. Development and seasonal variations of Lophodermium populations on Pinus thunbergii needle litter. Mycoscience 47: 242-247. 
Hirose D, Shirouzu T, Hirota M, Ohtsuka T, Senga Y, Du M, Shimono A, Zhang X, in press. Species richness and species composition of fungal communities associated with cellulose decomposition at different altitudes on the Tibetan Plateau. Journal of Plant Ecology, doi: 10.1093/jpe/rtp028.

Hudson HJ, 1968. The ecology of fungi on plant remains above the soil. New Phytologist 67: 837-874.

Hyde KD, Bussaban B, Paulus B, Crous PW, Lee S, McKenzie EHC, Photita W, Lumyong S, 2007. Diversity of saprobic microfungi. Biodiversity and Conservation 16: 7-35.

Kawahara T, 1975. Decomposition of litter on forest floor. II. Effect of the moisture of two kinds of leaf litter on their decomposition rates. Japanese Journal of Ecology 25: 71-75.

Kendrick WB, Burges A, 1962. Biological aspects of the decay of Pinus sylvestris leaf litter. Nova Hedwigia 4: 313-342.

Kinkel LL, Andrews JH, 1988. Disinfestation of living leaves by hydrogen peroxide. Transactions of the British Mycological Society 91: 523-528.

Koide K, Osono T, Takeda H, 2005. Fungal succession and decomposition of 
Camellia japonica leaf litter. Ecological Research 20: 599-609.

Miura K, Kudo M, 1970. An agar-medium for aquatic hyphomycetes. Transactions of the Mycological Society of Japan 11: 116-118 (in Japanese).

Olson J, 1963. Energy storage and the balance of producers and decomposers in ecological systems. Ecology 44: 322-331.

Osono T, 2002. Phyllosphere fungi on leaf litter of Fagus crenata: occurrence, colonization, and succession. Canadian Journal of Botany 80: 460-469.

Osono T, Takeda H, 1999a. Decomposing ability of interior and surface fungal colonizers of beech leaves with reference to lignin decomposition. European Journal of Soil Biology 35: 51-56.

Osono T, Takeda H, 1999b. A methodological survey on incubation of fungi on leaf litter of Fagus crenata. Applied Forest Science, Kansai 8: 103-108 (in Japanese with English abstract).

Osono T, Takeda H, 2001. Organic chemical and nutrient dynamics in decomposing beech leaf litter in relation to fungal ingrowth and successin during 3-year decomposition processes in a cool temperate deciduous forest in Japan. Ecological Research 16: 649-670. 
Osono T, Takeda H, 2002. Comparison of litter decomposing ability among diverse fungi in a cool temperate deciduous forest in Japan. Mycologia 94: 421-427.

Osono T, Hobara S, Fujiwara S, Koba K, Kameda K, 2002. Abundance, diversity, and species composition of fungal communities in a temperate forest affected by excreta of the Great Cormorant Phalacrocorax carbo. Soil Biology \& Biochemistry 34: 1537-1547.

Osono T, Fukasawa Y, Takeda H, 2003. Roles of diverse fungi in larch needle litter decomposition. Mycologia 95: 820-826.

Osono T, 2006. Fungal decomposition of lignin in leaf litter: comparison between tropical and temperate forests. In: Meyer W, Pearce C (Eds.), Proceeding of the 8th International Mycological Congress, Cairns, Australia, Medimond, Bologna, pp. 111-117.

Osono T, Takeda H, 2006. Fungal decomposition of Abies needle and Betula leaf litter. Mycologia 98: 172-179.

Osono T, Hobara S, Koba K, Kameda K, Takeda H, 2006a. Immobilization of avian excreta-derived nutrients and reduced lignin decomposition in needle 
and twig litter in a temperate coniferous forest. Soil Biology \& Biochemistry 38: 517-525.

Osono T, Hobara S, Koba K, Kameda K, 2006b. Reduction of fungal growth and lignin decomposition in needle litter by avian excreta. Soil Biology \& Biochemistry 38: 1623-1630.

Osono T, Hirose D, Fujimaki R, 2006c. Fungal colonization as affected by litter depth and decomposition stage of needle litter. Soil Biology \& Biochemistry 38: 2743-2752.

Osono T. 2007. Ecology of ligninolytic fungi associated with leaf litter decomposition. Ecological Research 22: 955-974.

Osono T, Takeda H, 2007. Fungi associated with Abies needles and Betula leaf litter in a subalpine coniferous forest. Canadian Journal of Microbiology 53: $1-7$.

Osono T, Ishii Y, Hirose D, 2008. Fungal colonization and decomposition of Castanopsis sieboldii leaf litter in a subtropical forest. Ecological Research 23: 909-917.

Osono T, Hirose D, 2009a. Ascomycete fungi associated with the bleaching of 
Quercus crispula leaf litter in Rishiri Island. Rishiri Research 28: 51-56.

(in Japanese with English abstract).

Osono T, Hirose D, 2009b. Altitudinal distribution of microfungi associated with Betula ermanii leaf litter on Mt. Rishiri, northern Japan. Canadian Journal of Microbiology 55: 783-789.

Osono T, Ishii Y, Takeda H, Seramethakun T, Khamyong S, To-Anun C, Hirose D, Tokumasu S, Kakishima M, 2009. Fungal succession and lignin decomposition on Shorea obtusa leaves in a tropical seasonal forest in northern Thailand. Fungal Diversity 36: 101-119.

Osono T, Hobara S, Hishinuma T, Abe JI, 2011. Selective lignin decomposition and nitrogen mineralization in forest litter colonized by Clitocybe sp. European Journal of Soil Biology 47: in press.

Parungao MM, Fryar SC, Hyde KD, 2002. Diversity of fungi on rainforest litter in North Queensland, Australia. Biodiversity and Conservation 11: $1185-1194$.

Paulus BC, Kanowski J, Gadek PA, Hyde KD, 2006. Diversity and distribution of saprobic fungi in leaf litter of an Australian tropical rainforest. 
Mycological Research 110: 1441-1451.

Promputtha I, Lumyong S, Lumyong P, McKenzie EHC, Hyde KD, 2002. Fungal succession on senescent leaves of Manglietia garrettii in Doi Suthep-Pui National Park, northern Thailand. Fungal Diversity 10: 89-100.

Pyzybyl K, Karolewski P, Oleksyn J, Labedzki A, Reich PB, 2008. Fungal diversity of Norway spruce litter: effects of site conditions and premature leaf fall caused by bark beetle outbreak. Microbial Ecology 56: 332-340.

Swift MJ, Heal OW, Anderson JM, 1979. Decomposition in terrestrial ecosystems. Blackwell, Oxford.

Takeda H, 1998. Decomposition processes of litter along a latitudinal gradient. In: Sassa K (Ed.), Environmental Forest Science. Kluwer, Dordrecht, pp. 197-206.

Tang AMC, Jeewon R, Hyde KD, 2005. Succession of fungal communities on decaying leaves of Castanopsis fissa. Canadian Journal of Microbiology 51: $967-974$.

Tian X, Takeda H, Azuma JI, 2000. Dynamics of organic-chemical components in leaf litters during a 3.5-year decomposition. European Journal of Soil 
Biology 36: 81-89.

Tokumasu S, 1998a. Fungal successions on pine needles fallen at different seasons: the succession of interior colonizers. Mycoscience 39: 409-416.

Tokumasu S, 1998b. Fungal successions on pine needles fallen at different seasons: the succession of surface colonizers. Mycoscience 39: 417-423.

Tokumasu S, 2001. Geographical distribution of Sporidesmium goidanichii in pine forests of Japan. Mycoscience 42: 575-589.

Tokumasu S, Aoki T, 2002. A new approach to studying fungal succession on decaying pine needles in an oceanic subtropical region in Japan. Fungal Diversity 10: 167-183.

Treseder KK, 2005. Nutrient acquisition strategies of fungi and their relation to elevated atmospheric $\mathrm{CO}_{2}$. In: Dighton J, White JF, Oudemans P (Eds.), The fungal community, 3rd ed., Taylor \& Francis, New York, pp. 713-731. 
T. Osono Table 1

Table 1. Tree species examined and study sites in Asian forests

\begin{tabular}{|c|c|c|c|c|c|}
\hline Tree species & Life form & Forest type & Study site & $\begin{array}{l}\text { Mean annual } \\
\text { temperature } \\
\left({ }^{\circ} \mathrm{C}\right)\end{array}$ & $\begin{array}{l}\text { Annual } \\
\text { precipitation } \\
(\mathrm{mm})\end{array}$ \\
\hline Betula ermanii & $\mathrm{D}, \mathrm{B}$ & Subalpine forest & Gifu, Japan & 2 & 2500 \\
\hline Abies mariesii, $A$. veitchii & $\mathrm{E}, \mathrm{C}$ & Subalpine forest & Gifu, Japan & 2 & 2500 \\
\hline Fagus crenata & $\mathrm{D}, \mathrm{B}$ & Cool temperate forest & Kyoto, Japan & 10 & 2495 \\
\hline Larix leptolepis & $\mathrm{D}, \mathrm{C}$ & Cool temperate forest & Nagano, Japan & 11 & 940 \\
\hline Chamaecyparis obtusa & $\mathrm{E}, \mathrm{C}$ & Warm temperate forest & Kyoto, Japan & 15 & 1474 \\
\hline Castanopsis sieboldii & $\mathrm{E}, \mathrm{B}$ & Subtropical forest & Okinawa, Japan & 22 & 2456 \\
\hline Shorea obtusa & $\mathrm{E}, \mathrm{B}$ & Tropical seasonal forest & Phayao, Thailand & 25 & 1155 \\
\hline
\end{tabular}

Life form: D deciduous, E evergreen, B broad-leaved, C coniferous. 
T. Osono Table 2

Table 2. Summary of results of isolation to examine fungal assemblages from leaf litter of seven tree species. Number of leaf disks examined and species richness (S), Simpson's diversity index (D), and equitability (E) of fungal assemblages on leaf litter examined with washing or surface disinfection methods are shown. ne, not examined.

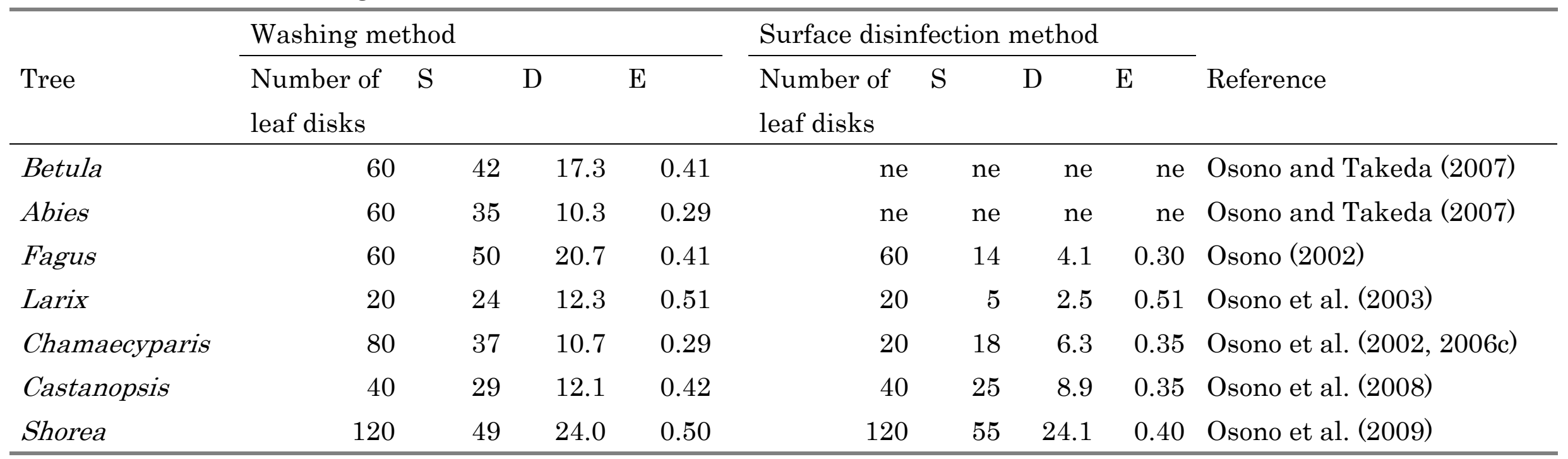

$\mathrm{D}=1 / \sum \mathrm{P} i^{2}, \mathrm{E}=\mathrm{D} / \mathrm{S}$, where $\mathrm{P} i$ is the proportion of the number of leaf disks with the $i$ th species relative to the total number of leaf disks tested. 
T. Osono Table 3

Table 3. Summary of results of pure culture decomposition tests to examine the ability of individual fungi to decompose leaf litter of seven tree species. Content of acid-hydrolyzable residue (AUR) in leaf litter and method of leaf litter sterilization, incubation period, the number of fungal species examined, and the minimum and maximum values of mass loss are shown. Incubation temperature was $20^{\circ} \mathrm{C}$ for all tests.

\begin{tabular}{|c|c|c|c|c|c|c|}
\hline Tree & $\begin{array}{l}\text { Method of leaf } \\
\text { litter sterilization }\end{array}$ & $\begin{array}{l}\text { AUR } \\
\text { content } \\
(\mathrm{mg} / \mathrm{g})\end{array}$ & $\begin{array}{l}\text { Incubation } \\
\text { period } \\
\text { (weeks) }\end{array}$ & $\begin{array}{l}\text { Number of } \\
\text { species }\end{array}$ & $\begin{array}{l}\text { Range of mass loss } \\
\text { (min, max) } \\
\text { (\% original mass) }\end{array}$ & Reference \\
\hline Betula & $\mathrm{EOG}, 60^{\circ} \mathrm{C}$ & 356 & 12 & 17 & $-2.5,15.5$ & Osono and Takeda (2006) \\
\hline Abies & $\mathrm{EOG}, 60^{\circ} \mathrm{C}$ & 415 & 12 & 8 & $-0.2,4.9$ & Osono and Takeda (2006) \\
\hline Fagus & $\mathrm{AC}, 120^{\circ} \mathrm{C}$ & 437 & 8 & 37 & $0.1,9.3$ & Osono and Takeda (2002a) \\
\hline Larix & $\mathrm{EOG}, 60^{\circ} \mathrm{C}$ & 454 & 12 & 11 & $-2.0,6.9$ & Osono et al. (2002) \\
\hline Chamaecyparis & $\mathrm{EOG}, 60^{\circ} \mathrm{C}$ & 372 & 12 & 12 & $4.3,12.1$ & Osono et al. (2006b) \\
\hline Castanopsis & $\mathrm{EOG}, 60^{\circ} \mathrm{C}$ & 262 & 12 & 11 & $0.6,21.5$ & Osono et al. (2008) \\
\hline Shorea & $\mathrm{EOG}, 60^{\circ} \mathrm{C}$ & 359 & 12 & 23 & $-1.7,24.7$ & Osono et al. (2009) \\
\hline
\end{tabular}

Method of sterilization: EOG ethylene oxide gas, AC autoclaving. 


\section{T. Osono Table 4}

Table 4. Major fungal genera isolated from leaf litter of seven tree species with washing and surface disinfection methods. Data of the top 15 fungi in terms of frequency of occurrence are shown. * indicates that bleaching activity was detected in pure culture tests.

\begin{tabular}{|c|c|c|c|c|c|c|c|}
\hline \multicolumn{8}{|c|}{ Washing method } \\
\hline Rank & Betula & Abies & Fagus & Larix & Chamaecyparis & Castanopsis & Shorea \\
\hline 1 & Trichoderma & Trichoderma & Clonostachys & Pestalotiopsis & Trichoderma & Trichoderma & Trichoderma \\
\hline 2 & Mucor & Volutella & Trichoderma & Cladosporium & Trichoderma & Trichoderma & Coelomycete $\mathrm{S} 1$ \\
\hline 3 & Volutella & Thysanophora & Trichoderma & Trichoderma & Penicillium & Trichoderma & Aspergillus \\
\hline 4 & Cladosporium & Mucor & Trichoderma & Penicillium & Umbelopsis & Lecanicillium & Cladosporium \\
\hline 5 & Trichoderma & Mortierella & Umbelopsis & Phoma & Umbelopsis & Pestalotiopsis & Trichoderma \\
\hline 6 & Hyphomycete B1 & Trichoderma & Penicillium & Clonostachys & Pestalotiopsis & Trichoderma & Trichoderma \\
\hline 7 & Mortierella & Umbelopsis & Phoma & Phialophora & Aspergillus & Cylindrocladium & Beltraniella \\
\hline 8 & Umbelopsis & Hyphomycete B2 & Arthrinium & Cladosporium & Penicillium & Umbelopsis & Beltrania \\
\hline 9 & Hyphomycete B2 & Paecilomyces & Cladosporium & Coelomycetes L1 & Cladosporium & Mucor & Verticillium \\
\hline 10 & Cladosporium & Pestalotiopsis & Mortierella & Epiococcum & Lecanicillium & Volutella & Nigrospora \\
\hline 11 & Epicoccum & Trichoderma & Umbelopsis & Umbelopsis & Penicillium & Penicillium & Penicillium \\
\hline 12 & Nodulisporium & Acremonium & Mucor & Penicillium & Penicillium & Pestalotiopsis & Penicillium \\
\hline 13 & Alternaria & - & Trichoderma & Penicillium & - & Paecilomyces & Nodulisporium \\
\hline 14 & - & - & - & Penicillium & - & Beltrania & Penicillium \\
\hline 15 & - & - & - & Penicillium & - & - & Fusarium \\
\hline
\end{tabular}




\begin{tabular}{|c|c|c|c|c|c|c|c|}
\hline \multicolumn{8}{|c|}{ Surface disinfection method } \\
\hline 1 & - & - & Xylaria* & Geniculosporium & Penicillium & Penicillium & Trichoderma \\
\hline 3 & - & - & Ascochyta & Hyphomycete L2 & Umbelopsis & Lachnocladiaceae $\mathrm{C} 1^{*}$ & Aspergillus \\
\hline 4 & - & - & Geniculosporium & Hyphomycete L3 & Umbelopsis & Pestalotiopsis & Trichoderma \\
\hline 6 & - & - & Coelomycete F1 & - & Trichoderma & Geniculosporium & Cladosporium \\
\hline 7 & - & - & Coelomycete F2 & - & - & Penicillium & Chaetomium \\
\hline 8 & - & - & Coelomycete F3 & - & - & Xylaria* & Fusarium \\
\hline 9 & - & - & Acrogenospora & - & - & Geniculosporium* & Muсоr \\
\hline 13 & - & - & Nodulisporium & - & - & Volutella & Gliocephalotrichum \\
\hline 14 & - & - & Phoma & - & - & - & - \\
\hline 15 & - & - & - & - & - & - & - \\
\hline
\end{tabular}




\section{T. Osono Table 5}

Table 5. Correlation coefficients for linear relationship between decomposition rate ( $\mathrm{k}$, /year) and climatic, litter quality, and fungal variables for leaf litter of seven tree species. W washing method, SD surface disinfection method. Decomposition rates were examined with litterbag methods in the field: Abies and Betula Tian et al. (2000), Fagus Osono and Takeda (2001), Larix Kawahara (1975), Chamaecyparis Osono et al. (2006a), Castanopsis Osono et al. (unpublished), Shorea Osono et al. (2009). $* * \mathrm{P}<0.01, * \mathrm{P}<0.05$, ns not significant. Data of mean mass loss by top five fungi for Fagus were not included in the analysis because the data were obtained in a pure culture decomposition test with a different method of leaf litter sterilization (i.e. autoclaving, see Table 3).

\begin{tabular}{lrrr}
\hline Explanatory variable & $\mathrm{R}$ & $\mathrm{N}$ \\
\hline Mean annual temperature & 0.788 & $*$ & 7 \\
Annual precipitation & -0.075 & $\mathrm{~ns}$ & 7 \\
Acid unhydrolyzable residue & -0.916 & $* *$ & 7 \\
Species richness (W) & -0.088 & $\mathrm{~ns}$ & 7 \\
Species richness (SD) & 0.636 & $\mathrm{~ns}$ & 5 \\
Simpson's diversity index (W) & 0.099 & $\mathrm{~ns}$ & 7 \\
Simpson's diversity index (SD) & 0.595 & $\mathrm{~ns}$ & 5 \\
Equitability (W) & 0.210 & $\mathrm{~ns}$ & 7 \\
Equitability (SD) & -0.114 & $\mathrm{~ns}$ & 5 \\
Mean mass loss by top five fungi (W) & 0.898 & $*$ & 5 \\
Mean mass loss by top five fungi (SD) & 0.418 & $\mathrm{~ns}$ & 4 \\
\hline
\end{tabular}


Figure legends

Fig. 1. Species richness and Simpson's diversity index (D) as a function of mean annual temperature (MAT). $\square$ Betula, - Abies, $\bigcirc$ Fagus, $\bigcirc$ Larix,

Chamaecyparis, $\nabla$ Castanopsis, $\diamond$ Shorea. Species richness: washing method, $\mathrm{R}=0.057, \mathrm{n}=7, \mathrm{P}=0.903$, not significant; surface disinfection method, $\mathrm{R}=0.736, \mathrm{n}=6$, $\mathrm{P}=0.095$. Simpson's D: washing method, $\mathrm{R}=0.307, \mathrm{n}=7, \mathrm{P}=0.503$, not significant; surface disinfection method, $\mathrm{R}=0.870, \mathrm{n}=6, \mathrm{P}=0.024$.

Fig. 2. Rarefaction curve showing the effect of the number of leaf disks examined on the number of fungi for seven tree species. W washing method, SD surface disinfection method.

Fig. 3. Frequency versus rank curves for fungal assemblages of seven tree species examined with washing and surface disinfection methods. Rank and frequency were converted to relative values. Symbols are as in Fig. 1. W washing method, SD surface disinfection method. 
Fig. 4. Similarity index of major fungal genera between tree species (a) and between washing (W) and surface disinfection (SD) methods (b).

Fig. 5. Decomposing ability of fungi isolated from leaf litter of seven tree species.

Decomposing ability denotes the mass loss values of leaves of respective tree species, expressed as the percentage relative to the original mass. Blank bars indicate that the fungi exhibited bleaching activity (see text); the taxon of the bleaching fungi is indicated as Basidiomycota (B) or Ascomycota (A).

Fig. 6. Decomposing ability of major fungi isolated from leaves of seven tree species. Decomposing ability denotes the mass loss values of leaf litter, expressed as the percentage relative to the original mass. Major fungi here indicate the top five species in terms of the rank of frequency of occurrence. $\square$ fungi with bleaching activity, $\mathbf{\square}$ fungi without bleaching activity. W washing method, SD surface disinfection method. 
T. Osono Fig. 1
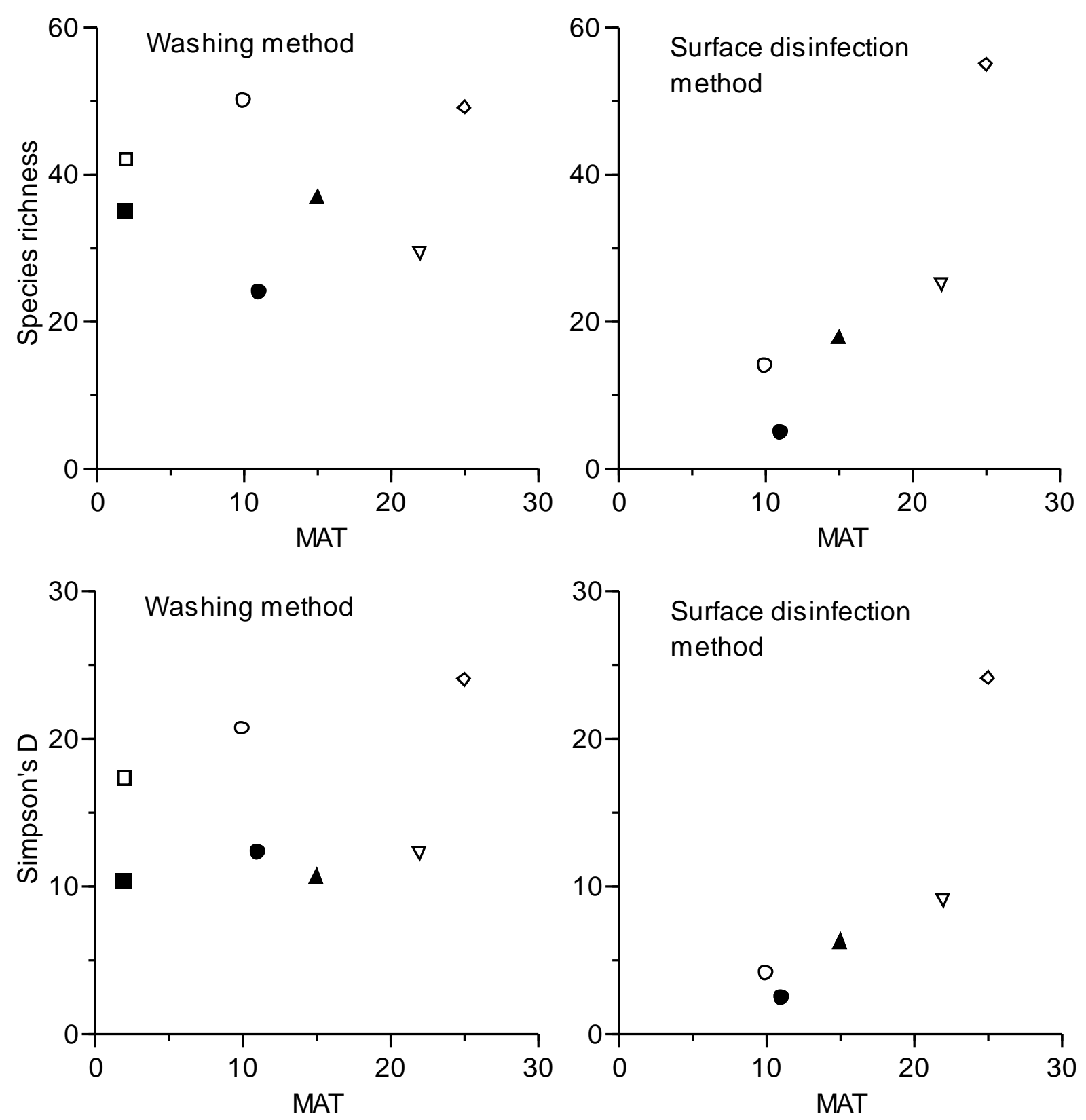
T. Osono Fig. 2
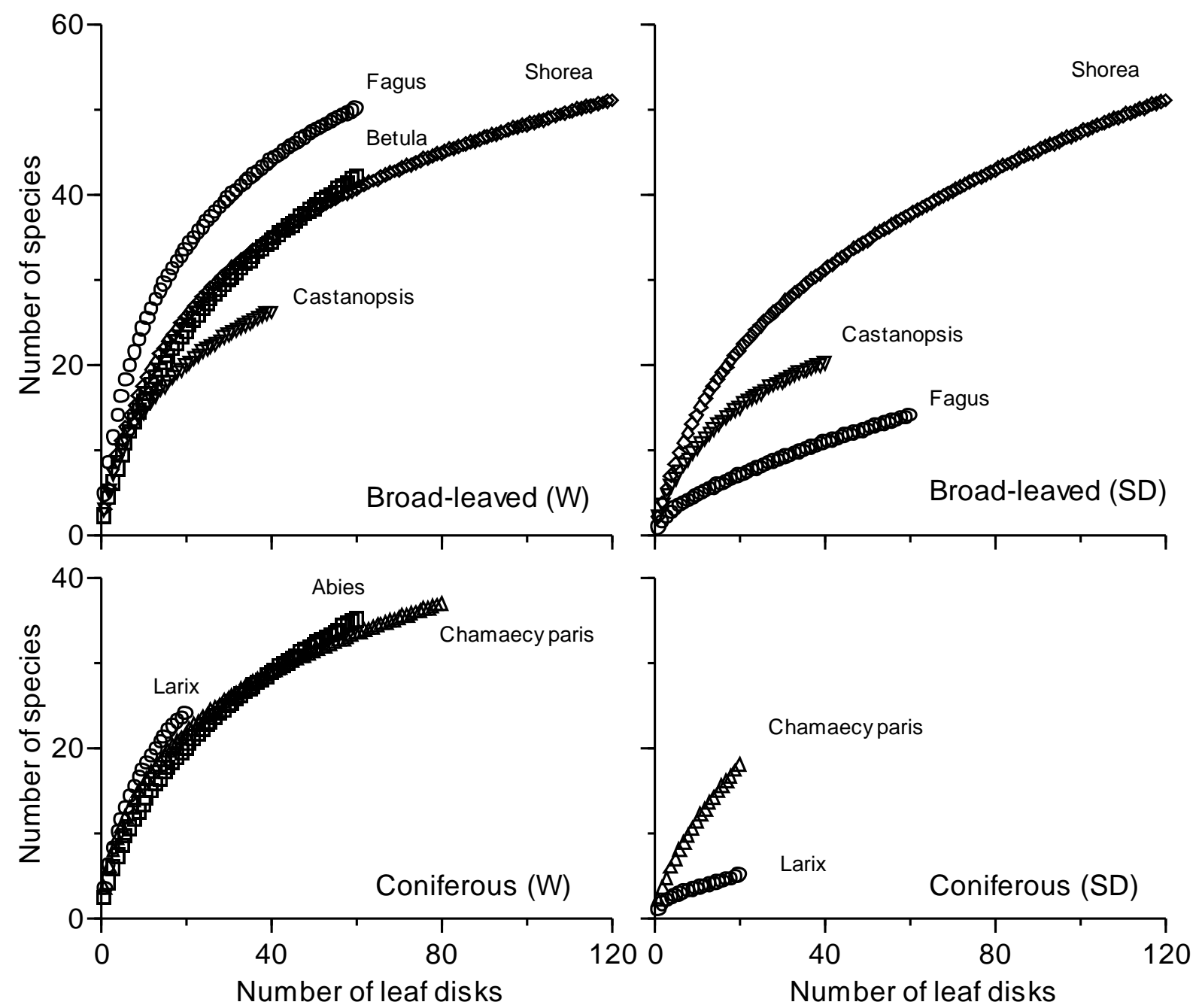
T. Osono Fig. 3
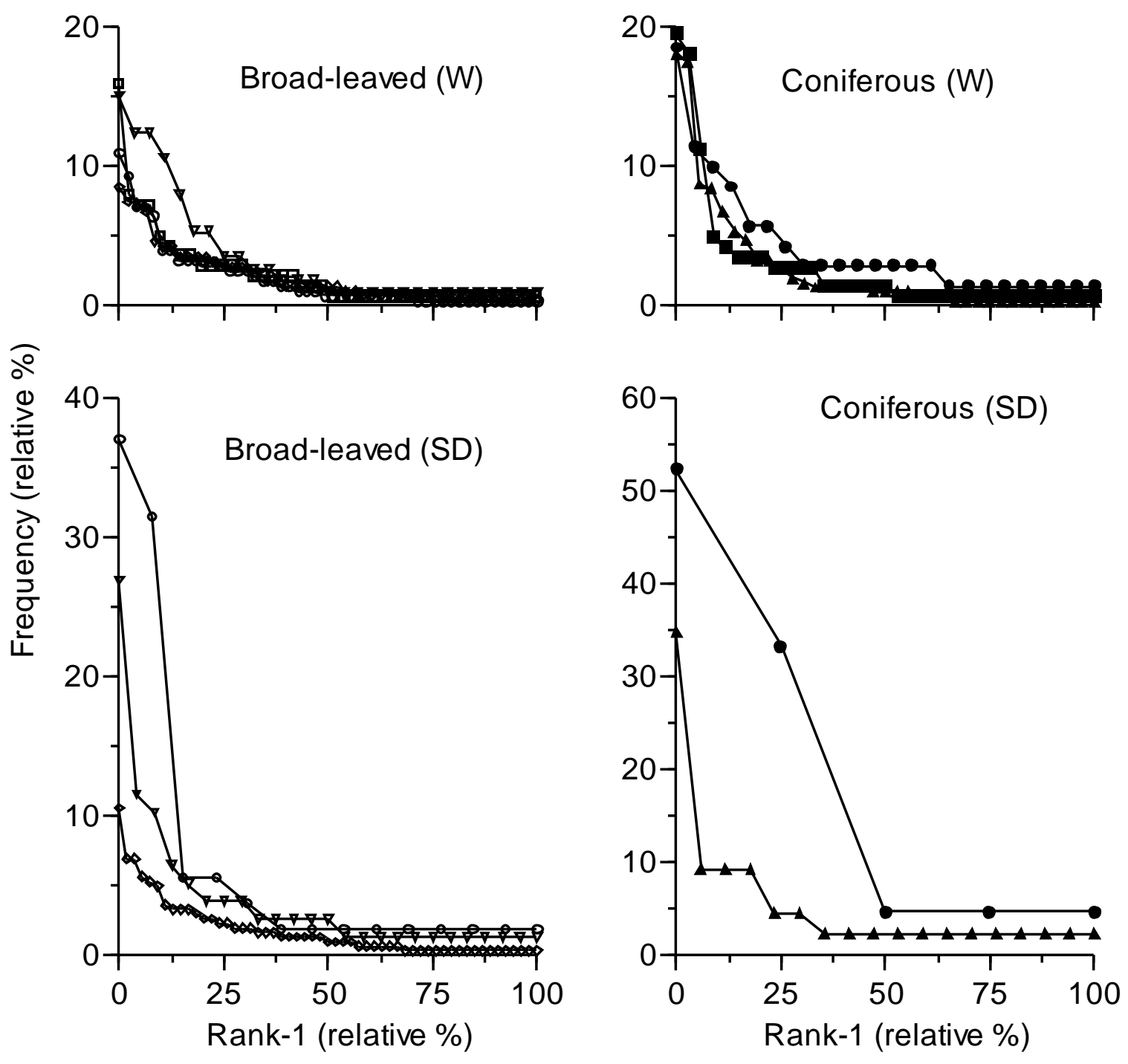
T. Osono Fig. 4

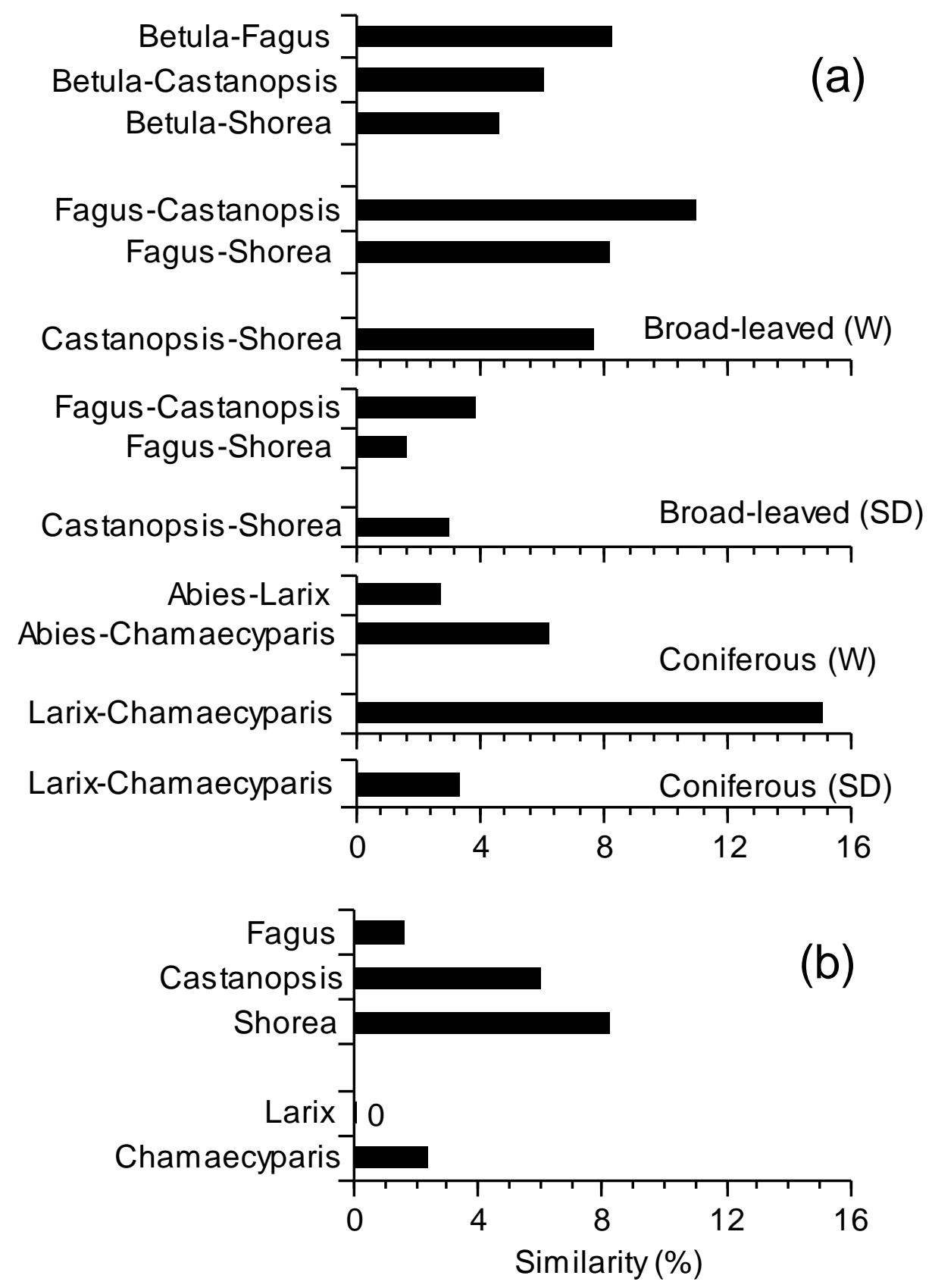


T. Osono Fig. 5
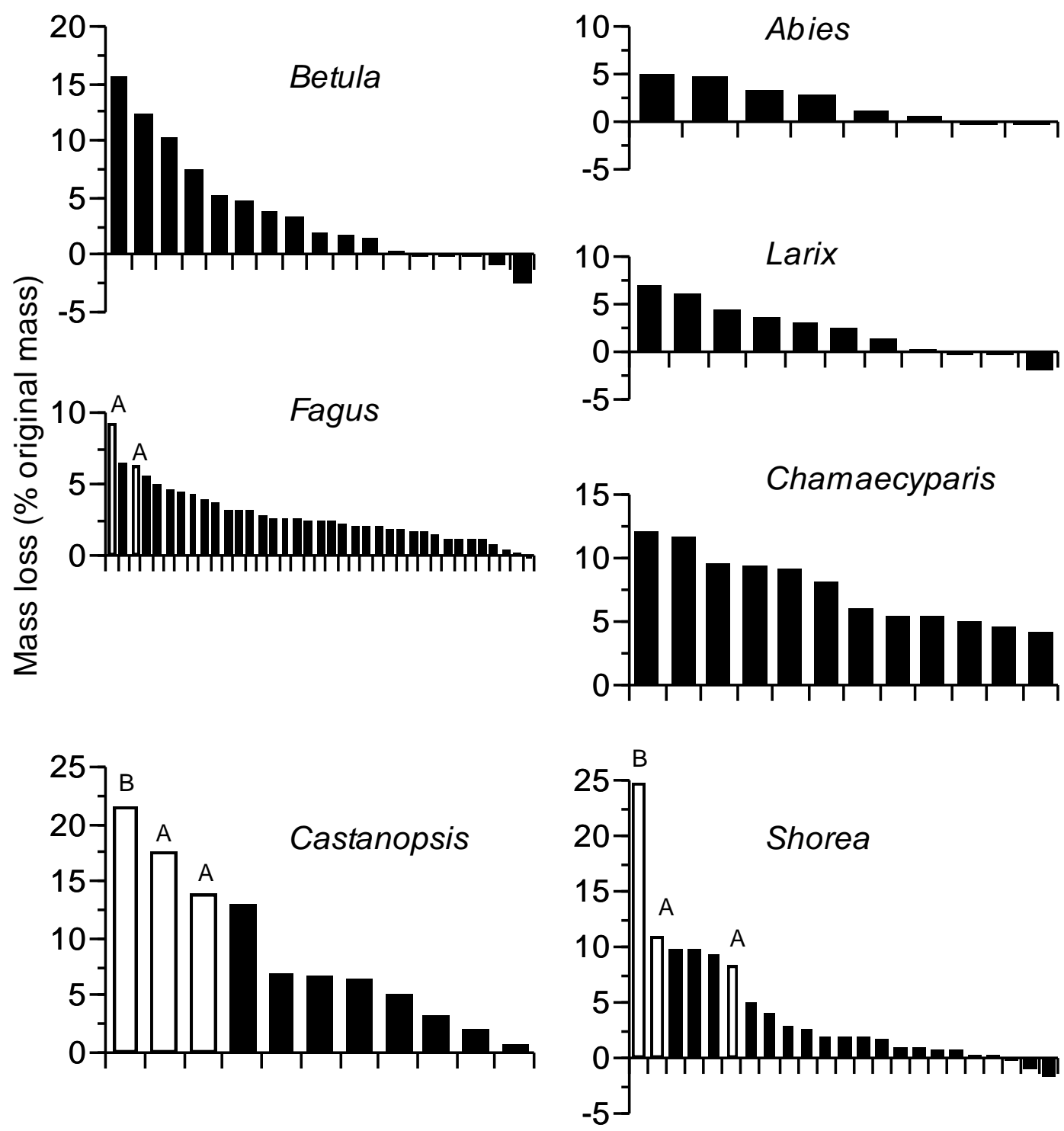

Rank of mass loss 
T. Osono Fig. 6
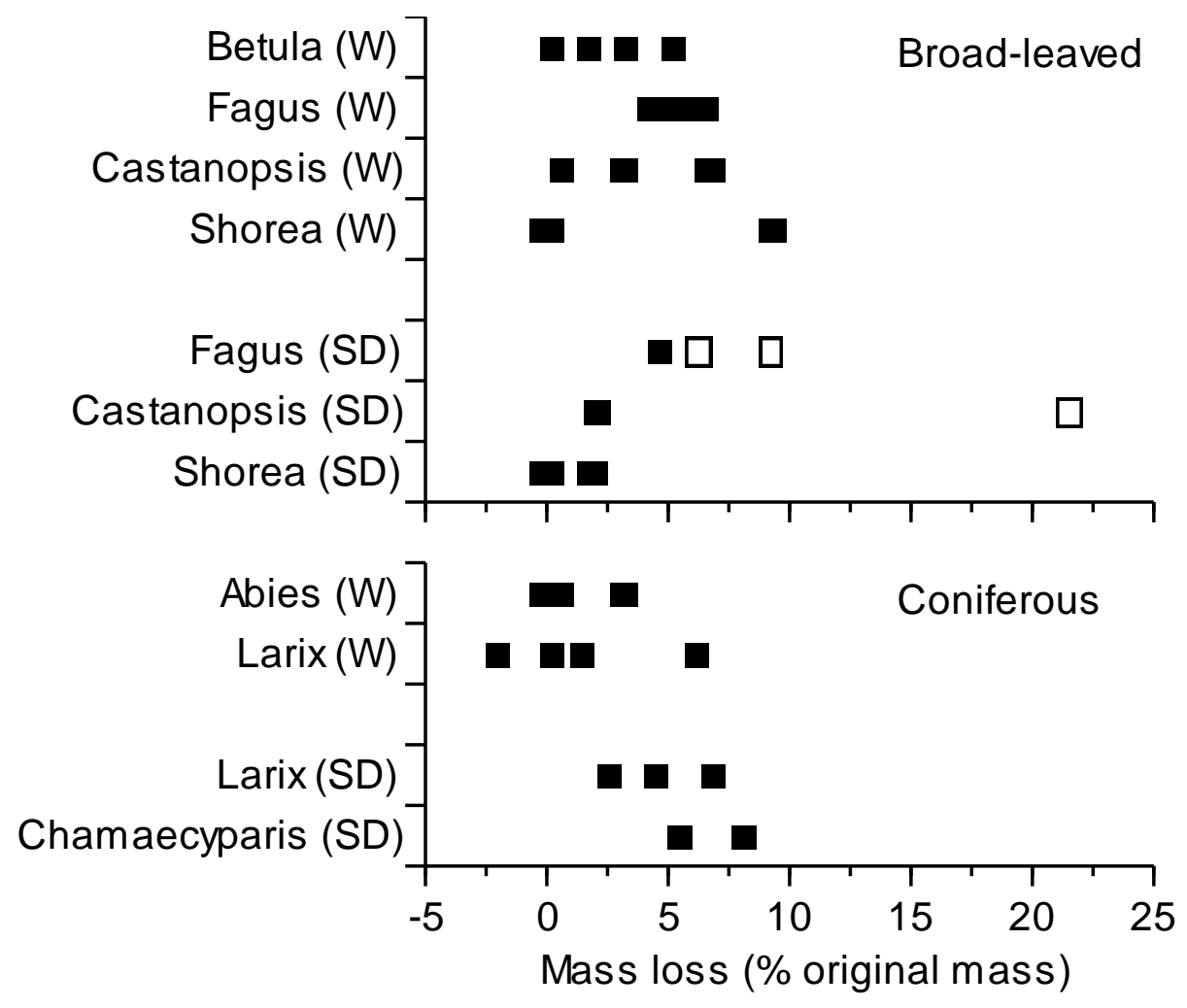